\title{
Corrigendum: Spatial and temporal distribution of foot-and-mouth disease in four districts situated along the Uganda-Tanzania border: Implications for cross-border efforts in disease control
}

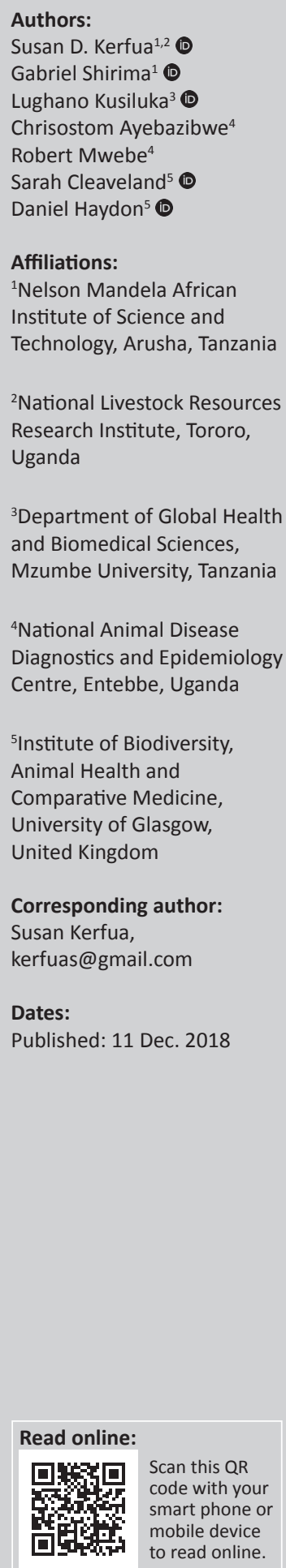

In the author list of this article published earlier, Chrisostom Ayebazibwe's name was unintentionally misprinted as 'Chrisostome'. The correct name is 'Chrisostom'. The author sincerely regrets this error and apologises for any inconvenience caused.
How to cite this article: Kerfua, S.D., Shirima, G., Kusiluka, L., Ayebazibwe, C., Mwebe, R., Cleaveland, S., et al., 2018, 'Corrigendum: Spatial and temporal distribution of foot-and-mouth disease in four districts situated along the Uganda-Tanzania border: Implication for cross-border efforts in disease control', Onderstepoort Journal of Veterinary Research 85(1), a1716. https://doi.org/10.4102/ojvr. v85i1.1716

Copyright: (C) 2018. The Authors. Licensee: AOSIS. This work is licensed under the Creative Commons Attribution License. Note: DOI of original article: https://doi.org/10.4102/ojvr.v85i1.1528 